\title{
TECHNIQUE OF THINKING STYLE EVALUATING
}

\author{
Dr. Alla Belousova, Head of Educational Psychology Department, \\ Southern Federal University, Rostov-on-Don, Russia; \\ E-mail:alla-belousova@newmail.ru \\ Dr. Vlada Pishchik, Head of Psychology Department, \\ Institute of Management, Business and Law, Rostov-on-Don, Russia; \\ E-mail: vladaph@yandex.ru
}

Received: August, 20.2015. Revised: November, 27.2015. Accepted: December, 02.2015. Original Article UDK 159.955.075

\begin{abstract}
The results of psychometric analysis of the new technique of thinking styles diagnostics are presented. The fundamental principles of thinking style concept by A. Belousova, according to which the thinking style is determined by the dominance of a person's function in the structure of thinking activity during the problem solving, are covered. In accordance with A. Belousova's ideas that the collaborative thinking activity as a self-organizing system is carried out by means of functions assumed by each participant: function of generating ideas, the function of selection (review and evaluation of information), functions of sense transfer and function of implementation. Thinking of adult, acting as a complex self-organizing system, combines the same functions: generation, selection, sense transfer and implementation. In this connection, we believe that the thinking style is defined as a characteristic set of functions actualized by a person in different situations of the problem solving. Domination of generation function determines the development of initiative thinking style, selection - critical, sense transfer - administrative, implementation - practical. The results of testing the reliability and validity of a new questionnaire for the thinking style diagnostics on a representative sample of Russians are given. The author's version of the questionnaire is presented.
\end{abstract}

Keywords: functions, thinking style, initiative, critical, administrative, practical.

\section{INTRODUCTION}

The growth of practical paradigm in psychology promotes the needs of psychologists for available modern express-methods that contribute to the solution of diagnostics tasks. In this context, the aim of this article

Corresponding Author

Dr. Alla Belousova, Head of Educational Psychology

Department, Southern Federal University,

Rostov-on-Don, Russia;

E-mail: alla-belousova@newmail.ru was to prove the new concept of thinking styles and presentation of validation results of the original technique that measures these thinking styles.

The concept of "thinking style" was introduced into a categorical system of psychological science, especially through the works of Harrison, A. F. and Bramson, R. M. (1984), Herrmann, N. (1995), Sternberg, R.J. (2002). In the broadest meaning of the word, thinking style is understood as the mental structures that allow people to process information and solve problems in a certain way.

The theory of thinking styles by Harrison, A. F. and Bramson, R. M. was very popular in Russia. In this theory, thinking style is understood as a system of intellectual strategies to which a person is predisposed by virtue of one's own individual characteristics. In accordance with the system of cognition that dominated in the research activity of the scientists, A. F. Harrison, R. M. Bramson identified certain thinking styles: dialectic (Hegel) - synthesizer; philosophical idealism (Kant) idealist; philosophical pragmatism (E. A. Singler) - pragmatist; symbolic logic (Leibniz) - analyst; empiricism (Locke) - realist. They identified 5 thinking styles: synthesizer, idealist, pragmatist, analyst, realist (Harrison, A. F. and Bramson, R. M., 1984).

Sternberg, R. J. (2002) defines the thinking style as the person's preferred way to use existing abilities. By analogy with the mental self-government of the state, he identifies in the structure of mental self-government of the person following elements: functions, forms, levels, fields, orientation. All these elements of mental self-government are the basis for the formation of the corresponding thinking styles: legislative, executive, judicial, monoarchical, hierarchical, oligarchical, anarchic, global, local, external, internal, conservative, progressive (Sternberg, R. J., 2002). 
The very idea of identification of functions seems very close to us, especially in the part where R. J. Sternberg uses the correlation and distribution of functions in the human activity as one of the criteria for identification of styles. In continuation of the dialogue, we want to say that we understand the human thinking not only as a self-governing system, but also as a self-organizing system, the implementation of which is made by means of functions. We think that functions hide more important mechanisms of self-organization of thinking in problem solving processes that are associated with the production of different new formations. Thus, criteria identified by R. J. Sternberg that characterize the thinking style, refer us to the issues of self-organization of thinking during the interaction of the person with the world, but also raise questions on the self-organization determination and the role in these processes of the emerging new formations, other people in a person's life. It seems that the possibility of correlation of the various functions performed by a person with the thinking style is heuristic.

Thus, in works of R. J. Sternberg, A. F. Harrison, R. M. Bramson, the ideas about the thinking style as a flexible, dynamic formation that changes depending on the situation, type of tasks, the age of the person, were developed. The concept of thinking style profile is introduced: for a person is characteristic not one style but the profile of styles.

Another line of thinking styles studies leads to the research field of psychophysiological mechanisms of individual differences in their conditioning of hemispheric asymmetry. In works of R. W. Sperry, R. Ornstein, H. Mintzberg, M. Gazzaniga it has been shown that the left hemisphere processes information analytically and consistently, and the right one - simultaneously and holistically. While developing these views, N. Herrmann offers four models of thinking styles: analytical, sequential or procedural, interpersonal or interactive, imaginary or holistic (Bawaneh et al, 2011; Herrmann, 1995).

If one tries to reduce the diversity of approaches, concepts and theories concerning the stylistic originality of thinking to some common grounds, then, in our opinion, one can identify three main directions.

The first direction - cognitive - centers around the issue of preferences for the certain representational system or the characteristics of the world image, representing the specifics of thinking style. In this case, the thinking is viewed through the originality of the psycho- logical mechanisms involved in the processes of the concept formation, information reflection (Berulava, 2001), or involved in the solution of cognitive tasks (Harrison, A. F. and Bramson, R. M., 1984; Cholodnaya, 2004).

The second direction - functional - is associated with the theories and concepts that directly or indirectly lead to the originality of representation of the various functions in thinking that develop the thinking style (Sternberg, R. J., 2002). The profile of the combination of various self-management functions (Sternberg, R. J., 2002), in which the thinking of person is carried out, defines the various thinking styles. This understanding of the nature of the thinking style shows that there are differences in the solution of cognitive tasks and these differences relate to what dominates in the processes of formulating and solving the problems - sensory-perceptual processes (of any modality or any representative system), thinking or emotions.

The third direction - psychophysiological - explores the psychophysiological basis of person's thinking originality. It seems to us that this direction acts as a key one, because, there is certainly a physiological conditioning of person's thinking originality. Person's thinking differs in its psychophysiological basis. And this is manifested in the specificity of the originality of person's thinking activity (Bawaneh et al, 2011; Herrmann, 1995).

Thus, if one tries to bring a variety of described concepts to a common denominator, one can say that they emphasize the dynamic characteristics of person's thinking activity. In other words, the characteristics of initiation and subsequent evolution of thinking in terms of entry of new knowledge into the psychological system, consciousness and life-world of person, in fact, determine the stylistic characteristics of person's thinking.

Our studies have shown (Belousova, 2014; Belousova, Pishchik, 2011) that in the collaborative thinking activity as a combined psychological system one observes the functional distribution in which each person assumes a certain function. We identified a list of functions, which mediate the thinking activity in the group while solving intellectual problems: that is functions of generation, selection, sense transfer and implementation. In this case, as our studies showed, in individual thinking activity one observes the same functions carried out by the particular person. Thus, with some degree of certainty, we believe that functions providing the collaborative thinking activity, constitute the content 
of individual thinking. This confirms the concepts of L. S. Vygotsky, P. Janet, J. Piaget that behind every higher mental function there are functional relationships of people.

Thus, we believe that thinking of adult, being a self-organizing psychological system, combines the following functions: generation, selection, sense transfer and implementation. This set characterizes the ingrained, sustainable functions of a person, which are based on the attitude to the new information. Thinking style is a profile of correlation of the functions of generation, selection, sense transfer, implementation in the process of development of new formations in solving intellectual problems. We can say that thinking style is defined as a characteristic set of functions actualized by a person in different situations of problem solving.

The correlation of the functions in the thinking of a particular person determines the direction of development of individual thinking by defining its stylistic originality. Thinking style can be defined as a sustainable combination of person's functions in relation to the new information associated with the characteristics of perception, production, systematization and implementation of information. Specificity of the thinking style is determined by the dominance among others of one of the functions in the structure of the individual profile of functions: with the dominance of the generation function - initiative thinking style is developing, with the dominance of the selection function - critical style, with the dominance of the sense transfer function - administrative thinking style, with the dominance of the implementation function - practical thinking style.

On the basis of a general understanding of functions through which thinking is realized, we have tried to build a model for each of the thinking styles.

Thinking style, which is determined by the main features of the generation function, was called initiative. The dominant feature is the function of generation of ideas. Generation function is based on the detection and resolution of cognitive conflicts, formation of new hypotheses, assumptions, decision options, objectives, plans that lead to a goal formation, motive formation, problem solving. Initiative thinking style is characterized by the directed search for contradictions, detection of problems and is manifested in the ability to put forward different assumptions, hypotheses. The most characteristic of this style is an attempt to initiate thinking, desire to "get to the bottom of everything", to understand the problem, when it discovered and realized beforehand.

Critical thinking style. The dominant feature is the selection function. In this case, the evaluation activity comes to the forefront by anticipating the productive, generating effects. The tendency to evaluate plans, hypotheses, objectives, knowledge, in general - the personality and activity of the other man (or others) is characteristic. Provided that the evaluation, criticism in the thinking activity prevail over the formulation of hypotheses, objectives, assumptions, new information, it can lead to low results, some sort of intellectual infertility.

Administrative thinking style is determined by the predominance of the sense transfer function. Sense transfer is required to bring people around a particular matter, it is firstly, and secondly to select the general hypothesis, objective, i.e. any general objective basis of activity around which it develops. For a person in whose thinking activity dominates this function, the coordination of the individual contribution and activity of the participants which essentially is reducible to managing the process is characteristic. It is in connection with the predominant implementation of activity in these directions the style has been identified as administrative.

Practical thinking style is associated with the predominance of the implementation function. This thinking style involves real changes in practice, during which naturally arise and develop new assumptions, hypotheses, however, their generation is connected with the practical realization of some ideas. In this case, we can say that the idea takes shape in action. It seems that a practical thinking style - a mental activity that has become dominant. For people with a prominent function of the implementation, it is important to try to solve the problem in practice, empirically.

\section{MATERIALS AND METHODS}

The variety of concepts of styles reflects less on the development of reliable means of measuring and evaluating the style.

Most foreign authors design thinking style by using a combination of different techniques: the Group Embedded Figures Test (GEFT) (Witkin et al, 1971); the Developing Cognitive Abilities Test (DCAT) (Beggs and Mouw, 1989); Critical Thinking Abilities (Torres and Cano, 1995); the Rational-Expe- 
riential Inventory (Norris and Epstein, 2011), and others. The presented techniques require adaptation process on the Russian sample in order to be available for national researchers.

Among the techniques in the Russian language that we know - technique by A. F. Harrison, R. M. Bramson, adapted by A.A. Alekseev (Alekseev and Gromova, 1993); techniques by M. A. Cholodnaya (Kholodnaya, 2004) and others. Each technique can reflect a small layer of issues related to the manifestations of person's thinking styles. In this regard, for the development of psychological knowledge it is of interest to develop new diagnostic tools for defining the thinking style of person.

For this purpose, the technique has been designed, aimed at thinking style diagnostics, which could confirm our theoretical constructs.

In the science of psychology is assumed that the technique is valid only if it has undergone the procedures of psychometric testing and meets the requirements: reliability, validity, accuracy and representativeness (Mitina, 2011; Pishchik, 2013).

In order to validate the technique of thinking styles by A. K. Belousova, we held its psychometric testing. To prove the belonging of presented propositions (total $n=32$ ) in the technique to the constructs of thinking styles (initiative - from now on - i, critical - c, administrative - a, practical - $\mathrm{p}$ ) we conducted a survey on a representative sample.

The sample of subjects was presented by students from various universities of Rostovon-Don $(\mathrm{N}=300)$. 145 - girls and 155 - boys, aged 18 to $25(\mathrm{M}=21)$.

When processing we used factor analysis to assess the content features of thinking styles. The results were processed using the application package SPSS - 20.

\section{RESULTS AND DISCUSSION}

The following results were obtained.

To analyze the structure of the connection of values of the studied technique we measured its factor validity, that is determined the factor structure and factor loadings results. By subjecting the data to factorization, we found 13 significant factors.
Figure 1. The dependence of the eigenvalue from the number of factors

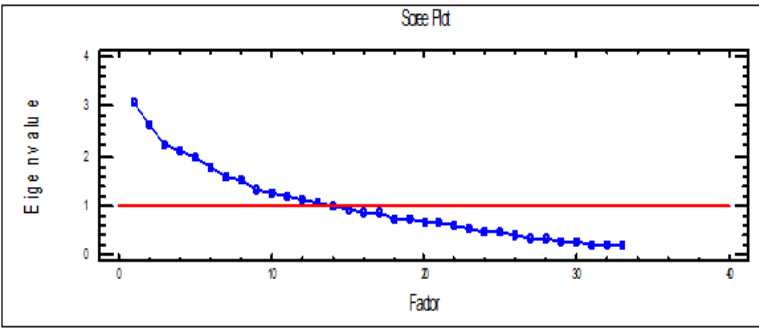

Figure 1. shows that there are thirteen significant factors. Load factors after rotation are shown in Table 1.

Table 1. Factor loadings of technique entries
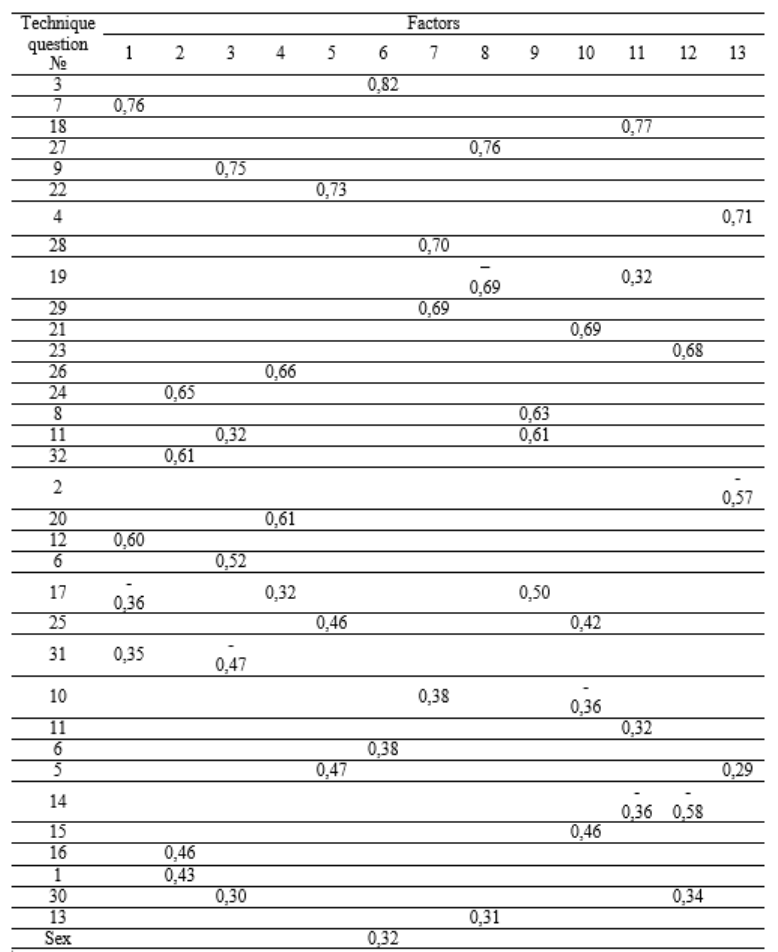

A content analysis of the factors showed. Factor 1 initiative correlates with the following variables: questions $12 \mathrm{a}, 17 \mathrm{a}, 2 \mathrm{c}, 31 \mathrm{c}, 7 \mathrm{i}$ and, $4 \mathrm{i}$. The maximum load is of the initiative style questions.

Factor 2 initiative-practical-critical correlates with the following variables: questions $1 \mathrm{i}, 16 \mathrm{c}, 24 \mathrm{p}, 32 \mathrm{i}$. The maximum load is of the practical style questions.

Factor 3 practical-critical correlates with the following variables: questions $9 p, 6 p$, 30i, 11c.

Factor 4 practical-critical correlates with the following variables: questions 20c, $26 \mathrm{p}, 15 \mathrm{i}$.

Factor 5 critical-practical correlates with the following variables: questions $22 p$, 25c, 5c.

Factor 6 administrative correlates with the following variables: questions 3,6 , sex. 
Factor 7 administrative-practical correlates with the following variables: questions 28a, 29p, 10i.

Factor 8 practical-initiative correlates with the following variables: $27 \mathrm{p}$ questions 19And, 13k.

Factor 9 administrative-critical correlates with the following variables: questions $11 \mathrm{c}, 8 \mathrm{a}, 17 \mathrm{a}$.

Factor 10 administrative correlates with the following variables: questions 21a, 15i, $25 \mathrm{c}, 10 \mathrm{i}$.

Factor 11 practical correlates with the following variables: questions $18 \mathrm{p}, 11,19,25$.

Factor 12 administrative - correlates with the following variables: questions $23 \mathrm{a}$, $14 \mathrm{a}, 30$.

Factor 13 initiative correlates with the following variables: questions $4 \mathrm{i}, 2,5$.

We managed to get factors for the individual styles: administrative, practical, initiative. With a clear predominance of practical style. So far, only critical style is presented as connected one. It correlates with the questions of administrative and practical styles.

To evaluate the effectiveness, differentiating value the technique has been tested to comply with psychometric standards.

In order to verify the reliability-stability of the technique we conducted the retest of the thinking styles on the same sample (cadets $\mathrm{N}=60$ ), two weeks after the presentation in 2013 and in 2014. Table 2 shows the results of correlation of the points of the first and second presentation for each item of the technique.

Table 2. Significant values of correlations between the scores of the first and second presentation

\begin{tabular}{ccc}
\hline $\begin{array}{c}\text { Technique } \\
\text { question № }\end{array}$ & $\begin{array}{c}\text { Correlation value } \\
\text { (significance } \\
\text { level 0.05) in } \\
\text { March 2013 }\end{array}$ & $\begin{array}{c}\text { Correlation value } \\
\text { (significance } \\
\text { level 0.05) in } \\
\text { October 2014 }\end{array}$ \\
\hline 1 & 0,36 & 0,49 \\
\hline 2 & 0,27 & 0,51 \\
\hline 4 & - & 0,78 \\
\hline 5 & 0,29 & - \\
\hline 6 & 0,21 & - \\
\hline 7 & - & 0,66 \\
\hline 8 & - & 0,45 \\
\hline 9 & - & 0,42 \\
\hline 11 & 0,37 & 0,46 \\
\hline 12 & 0,49 & 0,54 \\
\hline 14 & - & 0,60 \\
\hline 16 & - & 0,44 \\
\hline 18 & 0,54 & - \\
\hline 19 & 0,30 & - \\
\hline 20 & - & 0,57 \\
\hline 22 & - & 0,80 \\
\hline 23 & 0,24 & 0,68 \\
\hline 26 & 0,24 & 0,52 \\
\hline 27 & 0,32 & 0,69 \\
\hline 28 & 0,27 & - \\
\hline 29 & 0,49 & 0,44 \\
\hline 31 & 0,54 & - \\
\hline 32 & 0,26 & 0,69 \\
\hline & & \\
\hline
\end{tabular}

The major confirmation of the stability showed the entries of the test (1i, 2c, 12a, 18p, 23a, 26p, 27p, 29p, 31c), other entries of the technique showed moderate stability.

Reliability-consistency of technique scales was measured using Cronbach's formula. The highest was Cronbach coefficient on the practical style questions (0.80), which can confirm the high compatibility between the test questions. The questions on administrative style (0.74), critical style (0.76) and initiative style $(0.79)$ combine well with each other. These results indicate a high connectivity within each of the technique scales.

The correlation results between the different test entries were received and distributed according to the thinking styles in table 3.

The findings suggest a high correlation ratio between the scores on the technique scales entries, which indicates satisfactory consistency.

Before proceeding to the assessment of constructive and content validity, it was necessary to assess whether the distribution of the study results on the Russian sample correspond to Gaussian bell curve.

Evaluation of the distribution type was carried out on the experimental group $n=200$, 106 boys and 94 girls, with a statistical test of normality $\chi^{2}$. Empirical data on 4 technique scales have a distribution that is close to the normal. Taking into account the data on the distribution type, it was decided on the admissibility of parametric techniques of mathematical statistics for data processing and the possibility of constructing the standard norms.

Table 3. Correlation values between technique entries

\begin{tabular}{cccc}
\hline $\begin{array}{c}\text { Thinking } \\
\text { styles }\end{array}$ & $\begin{array}{c}\text { Technique } \\
\text { entries }\end{array}$ & $\begin{array}{c}\text { Correlation } \\
\text { values }\end{array}$ \\
\hline \multirow{4}{*}{ Administrative } & 8 & 12 & 0,62 \\
\cline { 2 - 4 } & 3 & 14 & 0,42 \\
\cline { 2 - 4 } & 3 & 17 & 0,31 \\
\hline \multirow{2}{*}{ Practical } & 6 & 23 & 0,38 \\
\hline \multirow{4}{*}{ Critical } & 6 & 22 & 0,18 \\
\hline \multirow{3}{*}{ Initiative } & 2 & 11 & 0,15 \\
& 2 & 16 & 0,39 \\
\hline & 11 & 25 & 0,33 \\
\hline & 13 & 20 & 0,39 \\
\hline & 1 & 7 & 0,11 \\
\hline & 4 & 7 & 0,17 \\
\hline
\end{tabular}

The content validity of the technique understood as the validity of the study procedures regarding the subject of the study was determined by virtue of the evaluation of consensus of psychological experts' opinions 
$(\mathrm{n}=8)$, evaluating the compliance of technique questions with their content loads. The reliability of expert evaluation was estimated on the basis of the concordance coefficient.

The results of the test entries evaluation by experts are shown in Table 4.

Table 4. Values of technique scales consistency

\begin{tabular}{lc}
\hline Technique scales & Concordance coefficient value \\
\hline 1. Initiative & 1.906 \\
\hline 2. Critical & 0.505 \\
\hline 3. Administrative & 0.679 \\
\hline 4. Practical & 0.459 \\
\hline
\end{tabular}

The high value of the concordance coefficient was obtained on all scales. This may indicate a high consistency of expert opinion on the content of scales entries. Based on the comments on the critical and practical styles questions, we have replaced the full wording of critical style questions and questions 22,26 in a practical style.

Empirical validity was measured using a statistical correlation of test scores and external parameters. Indicators of administrative thinking style were combined with an indicator of the success of managers as an external parameter. Indicators of practical thinking style were combined with the success of salespeople. The biserial correlation coefficient was calculated. Analysis of the results showed that there is no significant correlation between thinking style and external parameters. This may indicate that the external criterion, such as the success of the activity involves a combination of different thinking styles. And this, in turn, indirectly confirms the assumption that there are no pure thinking styles.

Using the technique, it is important to compare the results with the mean values for each scale. Below are the results of calculation of mean values according to the scales on a representative sample table 5 .

Table 5. The mean values and measures of values dispersion of thinking styles in a group of young people

\begin{tabular}{llcccc}
\hline \multirow{2}{*}{ № } & \multirow{2}{*}{ Thinking styles } & \multicolumn{2}{c}{ Men } & \multicolumn{2}{c}{ Women } \\
\cline { 3 - 6 } & & $\mathrm{M}$ & $\delta$ & $\mathrm{M}$ & $\delta$ \\
\hline \multirow{2}{*}{1} & Initiative & 20 & 3,12 & 19 & 2,81 \\
\hline 2 & \multirow{2}{*}{ Critical } & 21 & 3,24 & 21 & 3,19 \\
\hline \multirow{2}{*}{3} & \multirow{2}{*}{ Administrative } & 23 & 3,53 & 23 & 3,19 \\
\hline \multirow{2}{*}{4} & \multirow{2}{*}{ Practical } & 24 & 4,20 & 23 & 3,30 \\
\hline
\end{tabular}

Discriminant validity has been widely presented in various samples of our work (Belousova, Pishchik, 2011).
Thus, the technique has acquired the following functional form (Appendix).

\section{CONCLUSIONS}

1. Thinking style - a construct, which is still the subject to continuous loading of content. Thinking style can be considered as a trend, as a direction, as a functional definition. In concept by A. K. Belousova thinking style is understood as a unique combination of functions: generation, selection, sense transfer, implementation, where the dominance of one of the functions determines the development of the respective thinking style.

2. Technique that measures four thinking styles was presented. High scores on the initiative thinking style suggest that a person in the course of thinking activity plays a role of an initiator of action. The predominance of critical thinking style suggests that a person in the thinking activity is a critic of ideas, assumptions, actions. The predominance of administrative thinking style assumes that a person acts as a coordinator of actions during problem solving. The predominant practical thinking style motivates a person to a greater extent to the practical implementation of ideas. As a rule, we can talk about the development of the thinking style profile, which involves finding the ratio of thinking styles of a particular person.

3. Applying the methods of psychometric analysis we confirmed the validity and reliability of a new technique that measures thinking styles on a representative sample of Russian respondents.

4. The next step might be the adaptation of the technique on a sample of foreign respondents.

\section{ACKNOWLEDGEMENT}

We would like to thank our colleges for valuable feedback and making sure we was true to our research.

Thanks are also due to Dr. Galina Molohina and Dr. Tatiana Sinchenko, who were coinvestigators in this study.

We would like to thank to the research participants - all students: thank you for your participation, for without it, this research would not have been possible.

\section{Conflict of interests}

Authors declare no conflict of interest. 


\section{REFERENCES}

Alekseev, A. A., \& Gromova, L. A. (1993). Understand me correctly or the book how to find the style of thinking, to use effectively intellectual resources and to find mutual understanding with people (p. 352). St. - Petersburg, Economic school. (Алексеев А.А., Громова Л.А (1993). Поймите меня правильно. СПб.: Экономическая школа.)

Bawaneh, A. K. A., Abdullah, A. G. K., Saleh, S., \& Yin, K. Y. (2011). Jordanian students' thinking styles based on Herrmann whole brain model. International Journal of Humanities and social science, 1(9), 89-97. Retrieved 20.08.2013. http://www. ijhssnet.com/journals/Vol. 1 No. 9 Special Issue July 2011/12.pdf

Beggs, D. L., \& Mouw, J. T. (1989). Assessing dimensions of ability. American Testronics, Developing Cognitive Ability Test: Comprehensive assessment program. Chicago: American Testronics.

Belousova, A. (2014). Thinking Style as a Factor of Variable Cognitive Education. Procedia-Social and Behavioral Sciences, 149, 97-101. DOI: 10.1016/j.sbspro.2014.08.167.

Belousova, A. K. \& Pishchik, V. I. (2011). Thinking style. Rostov-on-Don: Publishing House of the $S F U, 167$

Berulava, G. A. (2001). Style of individuality: Theory and Practice. M., (Берулава Г.А. (2001). Стиль индивидуальности: теория и практика. М.: Педагогическое общество России).

Harrison, A. F., \& Bramson, R. M. (1984). The art of thinking. Random House (USA), New York: Doubleday.

Herrmann, N. (1995). The creative brain (2nd ed). Kingsport: Quebecor Printing Book Group.

Kholodnaya, M. A. (2004). Cognitive styles. On the nature of the individual mind, 2nd edn., Piter, Saint Petersburg.

Mitina, O. V. (2011). Development and adaptation of psychological questionnaires. M.: Smysl. (Митина, О.В. (2011) Разработка и адаптация психологических опросников. М.: Смысл.)

Norris, P., \& Epstein, S. (2011). An experiential thinking style: Its facets and relations with objective and subjective criterion measures. Journal of personality, 79(5), 1043-1080. doi: 10.1111/j.14676494.2011.00718.x

Pishchik, V.I. (2013) Psychometric testing methods for measuring type mentality generations, European researcher, 54(7-1), 1852-1866.

Sternberg, R.J. (2002). Thinking Styles. Reprinted Edition, UK, Cambridge University Press.

Torres, R. M., \& Cano, J. (1995). Critical thinking as influenced by learning style. Journal of Agricultural Education, 36, 55-63.

Witkin, H. A., Oltman, P. K., Raskin, E., \& Karp, S. A. (1971). Manual for embedded figures test, children's embedded figures test, and group embedded figures test. Palo Alto, CA: Consulting Psychologists Press, Inc. Related constructs and measures from beyond the field of ethics, 365 .

\section{APPENDIX}

\section{THINKING STYLES TECHNIQUE (Belousova, A. K.)}

\section{Instructions:}

"You are offered a series of statements. If the statement corresponds with your personal opinion, then answer "yes", if it is more likely to correspond, then answer is "probably yes", if it does not correspond - then answer "no", if it is more likely not to correspond, then - "probably no".

1. Every new topic for me is associated with a large number of emerging ideas.

2. "Weak" spots of the problem at hand immediately strike my eye.

3. I like to discuss problems with others. ideas.

4. I am a very good critic of my own

5. I leave out weaknesses of idea if I like it.

6. I easily reject old ideas for the practical implementation of new ideas.

7. In my group, I often suggest new ideas.

8. I often have to explain to others the meaning of ideas that were ambiguously presented by other people.

9. I do not always support new ideas due to the fact that I feel the need to continue working on old problems.

10. I can hardly formulate my emerging ideas.

11. I often get convinced that new ideas for problem solving are by no means new.

12. In group I sometimes take the responsibility to make the final decision.

13. I avoid criticizing other people's ideas.

14. I prefer to avoid discussions.

15. I always try to understand the problem and work out a strategy for its solution.

16. I find it interesting to divide a problem on specific tasks.

17. I find it interesting to listen to the opinions of others about various problems.

18. I believe that before rejecting the idea one should try to test it in practice.

19. I believe that the idea is good only if the possibility of its practical use is clear from the outset.

20. I find it difficult to evaluate the proposed ideas.

21. I believe that one should look for the 
answers to the questions in the literature, and do not ask other people's opinions on this issue.

22. A detailed and thorough execution of work makes me bored.

23. I like organizing the discussion of the problems.

24. I prefer bringing the implementation of ideas to a conclusion, even if others criticize them.

25. The development of proposed ideas prevails over their evaluations while working out of the problems.

26. The practical implementation of ideas is boring for me.

27 . I am primarily interested in the productive side of solution.

28. I am interested in the opinions of others about possible solutions.

29. I find it difficult to put into action the plans developed for problem solving.

30. My suggestions are usually obvious and understandable to others.

31. As a rule, the analysis of the problems does not appeal to me.

32. I like to influence people, to guide them in the process of problem solving.

\section{The Answers:}

1. Process the answers under the following numbers according to the scheme: no $=1$

Yes $=4$, probably yes $=3$, probably no $=2$,

Initiative thinking style $-1,7,10,15,32$

Critical thinking style - 2, 11, 16 17,23

Administrative thinking style - 3, 8, 12 ,

Practical thinking style - 9, 18, 24, 27

2. Process the answers under the following numbers according to the scheme: no $=4$

Yes $=1$, probably yes $=2$, probably no $=3$,

Initiative thinking style - 4, 19, 30

Critical thinking style - 5, 13, 20, 25, 31

Administrative thinking style - 14, 21,

28

Practical thinking style - 6, 22, 26, 29

3. Sum the obtained scores for each thinking style 